\title{
Febre de origem indeterminada: relato de um diagnóstico inesperado
}

Cristiana Santos Antunes ${ }^{1}$, Mariana Costa Figueiredo', Filipe Fernandes Bacalhau' ${ }^{1}$, Francisco Ferreira Silva ${ }^{1}$, Maria Esmeralda Covas Amador ${ }^{1}$, Luís Miguel Duque ${ }^{2}$

\section{RESUMO}

Introdução: A síndroma de febre de origem indeterminada (FOI) clássica é definida pela presença de temperatura corporal superior a $38,3^{\circ} \mathrm{C}$ com duração superior a três semanas, sem diagnóstico definido, apesar de investigação apropriada durante três consultas em ambulatório ou três dias em internamento hospitalar. Implica a realização de uma avaliação criteriosa pelo médico de família, da qual deve resultar uma marcha diagnóstica adequada. Entre as múltiplas etiologias possíveis, a infeção pelo vírus de imunodeficiência humana (VIH) é uma entidade a ter em conta, nomeadamente na presença de fatores de risco para a mesma. Descrição do Caso: Mulher de 47 anos, raça caucasiana, com antecedentes pessoais de neoplasia do colo do útero submetida a conização há quatro anos. É fumadora, sem hábitos alcoólicos ou toxicofílicos conhecidos. Divorciada, integra uma família monoparental desde 2005, sem vida sexual ativa há cerca de oito anos. Recorre a consulta de doença aguda por quadro de mal-estar geral, cansaço, febre de predomínio vespertino e tosse seca com várias semanas de evolução. Após as primeiras etapas de investigação, a etiologia mantinha-se indeterminada, apesar da recorrência dos sintomas. Perante o quadro clínico de síndroma de FOI foi realizada investigação etiológica mais alargada, da qual se destaca serologia positiva para $\mathrm{VIH}-1$. A utente foi referenciada para consulta de infeciologia e medicada com antirretrovirais e terapêutica dirigida a pneumocistose, uma doença definidora de síndroma de imunodeficiência adquirida (SIDA). Este diagnóstico teve um impacto profundo a nível pessoal, familiar e social, com necessidade de seguimento em consulta de psicologia e psiquiatria.

Comentário: A investigação etiológica da síndroma de FOI neste caso clínico conduziu a um diagnóstico inesperado de SIDA, o que sensibilizou a equipa clínica para a importância do rastreio atempado de VIH, para a correta abordagem da síndroma de FOI e para a importância do acompanhamento longitudinal pelo médico de família, de acordo com o diagnóstico estabelecido.

Palavras-chave: Infeção VIH; Síndroma de imunodeficiência adquirida; Febre de origem indeterminada; Pneumocistose.

\section{INTRODUÇÃO}

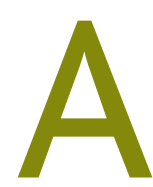

febre é um sintoma comum na prática clínica em medicina geral e familiar (MGF), sendo habitualmente autolimitada, com tratamento sintomático e/ou dirigido à etiologia. A síndroma de febre de origem indeterminada (FOI) foi descrita pela primeira vez por Petersdorf e Beeson em $1961,{ }^{1-6}$ tendo a definição sofrido diversas modificações ao longo do tempo.

Em 1991, Durack e Street reviram a definição original, sendo esta síndroma definida atualmente como uma elevação de temperatura corporal superior a

1. USF Amora Saudável. Amora, Portugal.

2. Hospital Garcia de Orta. Almada, Portugal. $38,3^{\circ} \mathrm{C}$ durante pelo menos três semanas, sem diagnóstico definido, apesar de investigação adequada em internamento hospitalar durante três dias ou investigação em ambulatório durante três consultas. ${ }^{1-2,4-6}$ Estes autores propuseram também uma classificação para a síndroma de FOI ajustada à prática clínica, subdividindo-a em quatro diferentes grupos: 1) FOI clássica; 2) FOI nosocomial; 3) FOI neutropénica; 4) FOI associada a VIH. ${ }^{1-2,4-7}$

Relativamente à FOI clássica, a etiologia pode ser subdividida em infeciosa (11-57\%), inflamatória não-infeciosa (1-31\%), neoplásica (8-13\%) e miscelânea. ${ }^{1,-3,7}$ A FOI associada a $\mathrm{VIH}^{1,2,4-7}$ pressupõe um diagnóstico prévio de VIH, o que remete para um grupo de etiologias que, neste grupo, têm um papel relevante, 
denominadas infeções oportunistas, nomeadamente Mycobacterium tuberculosis, Pneumocystis jiroveci, Citomegalovírus (CMV), entre outras. .,6-9 $^{4}$

Segundo os dados epidemiológicos de 2019 da Organização Mundial da Saúde (OMS), o VIH afeta cerca de 38 milhões de pessoas em todo o mundo, com uma incidência de 1,7 milhões no referido ano. ${ }^{9}$ No entanto, apesar de um aumento da prevalência da doença a nível mundial, tem-se verificado uma diminuição da incidência e da mortalidade devido ao diagnóstico mais precoce e à eficácia das atuais terapêuticas. A SIDA corresponde ao estádio mais avançado de infeção porVIH, caracterizado por CD4+<200/uL e/ou doença definidora de SIDA..$^{8-9}$

Segundo as normas de orientação clínica da Direção-Geral da Saúde (DGS), o rastreio laboratorial de VIH está recomendado para todos os indivíduos com idade compreendida entre os 18 e 64 anos (pelo menos uma vez na vida) ou em certos grupos de risco, nomeadamente indivíduos a quem foi diagnosticada uma infeção sexualmente transmissível (IST). ${ }^{10}$

A escolha deste caso clínico foi motivada pelo facto de a investigação da síndroma de FOI ter conduzido a um diagnóstico inesperado de uma patologia atualmente cada vez mais rara (SIDA). O médico de família apresenta um papel essencial na prevenção primária e na prevenção secundária de IST (designadamente através da realização de rastreios, quando indicado). Além disso, perante um quadro clínico de FOI é importante manter um elevado grau de suspeição clínica e realizar uma abordagem diagnóstica sistemática, orientada pela história clínica e pelo exame objetivo e dirigida às possíveis causas, das mais para as menos prováveis. Este relato de caso pretende, portanto, sensibilizar para a importância do rastreio de VIH, para a correta abordagem diagnóstica da síndroma de FOI e para a importância do acompanhamento longitudinal, de acordo com o diagnóstico estabelecido.

\section{DESCRIÇ̃̃O DO CASO}

Mulher de 47 anos, de raça caucasiana, residente na zona de Setúbal. Tem como habilitações literárias o $12^{\circ}$ ano de escolaridade e trabalha como administrativa. Divorciada há 15 anos, tem dois filhos de 22 e 18 anos, integrando uma família monoparental. Sem vida sexual ativa nos últimos oito anos.
Relativamente aos seus antecedentes pessoais salienta-se o diagnóstico de neoplasia do colo do útero, submetida a conização em 2016 com cura, atualmente sem seguimento em consulta de ginecologia e com citologia cervico-vaginal atualizada, com resultado negativo para lesão intra-epitelial ou malignidade (NILM). Dos antecedentes obstétricos destaca-se um índice obstétrico 2-0-0-2 (dois partos de termo eutócicos em 1998 e 2003). Sem medicação habitual. É fumadora de 20 cigarros por dia desde há 15 anos (15 unidades maço-ano), sem hábitos alcoólicos ou toxicofílicos. O plano de vacinação está atualizado. Não apresenta antecedentes familiares de relevo.

A utente recorreu à consulta de doença aguda na sua unidade de saúde familiar (USF), em janeiro de 2020, por um quadro com cerca de uma semana de evolução, caracterizado por mal-estar geral, cansaço, temperatura corporal vespertina subfebril (temperatura máxima $37,5^{\circ} \mathrm{C}$ ), tosse seca e, por vezes, dispneia associada. Não apresentava alterações de relevo ao exame objetivo. Optou-se por iniciar terapêutica sintomática e antibioterapia com azitromicina 500mg (um comprimido por dia durante três dias), assumindo como hipótese diagnóstica uma pneumonia atípica. Foi ainda requisitada uma radiografia torácica.

Reagendou consulta após duas semanas, referindo melhoria da dispneia, mas mantendo queixas de mal-estar geral, cansaço, tosse, picos febris vespertinos (temperatura máxima de $38,5^{\circ} \mathrm{C}$ ) e hipersudorese de predomínio noturno. Apresentava ainda queixas de anorexia e perda ponderal de $4 \mathrm{~kg}$ desde a última consulta. Negava hemoptises e contexto epidemiológico conhecido de relevo. A radiografia torácica não apresentava alterações. Atendendo à clínica, e colocando como principal hipótese de diagnóstico o diagnóstico de tuberculose pulmonar, optou-se por pedir avaliação analítica (com hemograma e marcadores inflamatórios) e tomografia computorizada (TC) pulmonar, mantendo medidas gerais e de controlo sintomático.

Após três semanas agendou nova consulta de reavaliação para mostrar o resultado dos exames pedidos, referindo encontrar-se assintomática há uma semana. Ao exame objetivo apresentava aspeto emagrecido, sem outras alterações. Dos MCDT pedidos na consulta anterior destacava-se, na avaliação analítica, anemia normocítica normocrómica, leucopenia, elevação da 
velocidade de sedimentação (VS) e da ferritina. Na TC pulmonar foram descritas alterações fibróticas em ambas as regiões apicais. Atendendo ao facto de, nesse momento, a utente se encontrar assintomática optou-se por não prosseguir na investigação (assumindo quadro autolimitado) e manter cuidados gerais.

No entanto, após duas semanas, a utente contactou novamente a USF, referindo reinício de queixas de cansaço para médios esforços e reinício de picos febris vespertinos diários (temperatura corporal máxima $39,0^{\circ} \mathrm{C}$ ) com uma semana de evolução. Foi agendada uma consulta presencial nesse mesmo dia para reavaliação completa da anamnese e exame objetivo e realização de investigação etiológica da síndroma de FOI.

Nesta consulta, para além dos aspetos anteriormente referidos, destacavam-se cinco adenopatias infracentimétricas inguinais bilaterais e uma perda ponderal de $11 \mathrm{~kg}$ desde o início do quadro. Procurando realizar o diagnóstico diferencial entre etiologia infeciosa, neoplásica e inflamatória ou autoimune foram pedidos novos MCDT: avaliação analítica (incluindo serologias e eletroforese de proteínas), ecografia abdominal, eletrocardiograma e ecocardiograma.

A avaliação analítica foi sobreponível à anterior (anemia, leucopenia, elevação da VS e da ferritina). Apresentava também elevação da desidrogenase láctica (LDH), hipergamaglobulinemia e hipoalbuminemia e serologia VIH-1 positiva (sendo as restantes serologias negativas). A ecografia abdominal, o eletrocardiograma e o ecocardiograma não apresentavam alterações valorizáveis.

Perante a serologia positiva para VIH-1, após confirmação da infeção explicou-se à doente o significado do diagnóstico, a abordagem terapêutica e o prognóstico. Procurando esclarecer a via de transmissão, a utente referiu que o ex-companheiro da relação que tivera há oito anos apresentava história de abuso de drogas injetáveis e outros comportamentos de risco, sendo, portanto, a via sexual o modo de transmissão mais provável.

Foi contactado o serviço de infeciologia do hospital de referência, tendo a utente iniciado seguimento em consulta hospitalar no dia seguinte. Durante o seguimento em consulta hospitalar, e atendendo aos sintomas respiratórios descritos, foi feito o diagnóstico de infeção por Pneumocystis jirovecii. Sendo esta uma doen- ça definidora de SIDA e atendendo à contagem de células $\mathrm{CD} 4+<200$ células/ $\mu \mathrm{L}$ foi confirmado o diagnóstico de SIDA. Iniciou-se terapêutica antirretroviral e terapêutica dirigida à pneumocistose, com evolução clínica favorável.

Atualmente a utente mantém seguimento em consulta de infeciologia, cumprindo terapêutica e mantendo carga viral indetetável e contagem leucocitária normal, com recuperação progressiva do seu bem-estar físico. No entanto, salienta-se o impacto negativo que este diagnóstico teve no seu bem-estar emocional e psicológico. A utente desenvolveu sintomatologia depressiva, com necessidade de acompanhamento em consulta de psicologia, associado a terapêutica farmacológica com sertralina $50 \mathrm{mg} /$ dia.

$\mathrm{Na}$ última consulta de medicina geral e familiar, a utente apresentava melhoria do humor, tendo retomado atividade laboral sem intercorrências. No entanto, mantém revolta pela noção de cronicidade da patologia e dificuldade na aceitação do diagnóstico, sobre o qual guarda segredo perante familiares e amigos. Este estado emocional tem conduzido a algum isolamento social e falta de apoio familiar, bem como rejeição de novos relacionamentos afetivos, sendo os cuidados de saúde primários e secundários o seu principal pilar de suporte.

\section{COMENTÁRIO}

A síndroma de FOI é uma entidade pouco frequente em MGF, sendo que, quando surge, deve-se mais frequentemente a uma apresentação atípica de uma doença comum do que à apresentação de uma doença rara. No presente caso clínico, a etiologia identificada foi a infeção por VIH, com diagnóstico concomitante de doença definidora de SIDA (entidade atualmente rara, devido à deteção e tratamento cada vez mais precoces de infeção por VIH).

Este relato apresenta um caso de síndroma de FOI clássica, apesar da associação ao diagnóstico de infeção por VIH, dado este diagnóstico ser inicialmente desconhecido. A FOI clássica compreende um vasto leque de etiologias possíveis (infeciosas, neoplásicas, inflamatórias, autoimunes ou mistas). O médico de família deve manter um elevado grau de suspeição clínica e uma abordagem sistemática, de modo a não atrasar o diagnóstico etiológico desta síndroma sem que, 
por outro lado, se realizem exames complementares invasivos e/ou desnecessários.

A utente cumpriu critérios de síndroma de FOI na terceira consulta, por ter apresentado febre com cerca de quatro semanas de evolução, de etiologia desconhecida após investigação etiológica inconclusiva dirigida às causas mais prováveis (pneumonia atípica e tuberculose pulmonar). No entanto, atendendo à melhoria clínica, optou-se nesse momento por não prosseguir a investigação etiológica, assumindo-se patologia autolimitada, facto que terá contribuído para um atraso no diagnóstico. Perante o reinício dos sintomas foi necessário reavaliar a utente, revendo cuidadosamente a anamnese e o exame objetivo, alargando o leque de hipóteses diagnósticas e consequente investigação.

A investigação diagnóstica inicial da FOI implica a realização de uma anamnese completa, exame objetivo detalhado, avaliação analítica e imagiológica seletivas. Não existe uma abordagem consensual relativamente aos MCDT recomendados. Numa primeira fase, os MCDT a realizar devem incluir: hemograma completo, creatinina, fosfatase alcalina (FA), aspartato aminotransferase (AST), alanina aminotransferase (ALT), VS, proteína-C reativa (PCR), LDH, creatinina cinase (CK), ferritina, anticorpos antinucleares (ANA), fator reumatoide (FR), eletroforese de proteínas, análise sumária de urina, hemoculturas, radiografia do tórax e ecografia abdominal..$^{1-5,7}$ As serologias para VIH devem também ser incluídas na abordagem inicial em doentes com fatores de risco para a infeção (como era o caso da utente deste caso clínico). ${ }^{5}$

Os restantes MCDT deverão ser orientados pelas potenciais pistas diagnósticas e os resultados das avaliações laboratorial e imagiológica iniciais. Estes poderão incluir as restantes serologias (hepatites B e C e VIH, caso esta não tenha sido incluída na avaliação inicial), ecocardiograma, teste de tuberculina, TC toraco-abdomino-pélvica, tomografia por emissão de positrões (PET), biópsia de adenopatias, biópsia medular, biópsia hepática, entre outros. ${ }^{1-5,7}$

No caso clínico descrito, apesar de ter realizado rastreio para VIH com resultado negativo durante as gravidezes, a doente apresentava como fator de risco para esta infeção o diagnóstico de infeção pelo vírus do papiloma humano (HPV). A neoplasia do colo do útero pode corresponder a um indício desta imunodeficiên- cia, dada a maior prevalência de cancro relacionado com HPV em pessoas seropositivas, associado aos hábitos tabágicos conhecidos. ${ }^{11-12}$ Segundo a Norma de Orientação Clínica n. ${ }^{\circ}$ 058/2011, da DGS, o diagnóstico de IST constitui critério para rastreio de infeção por $\mathrm{VIH} .{ }^{10}$

O facto de não ter sido realizado o rastreio de infeção por VIH aquando do diagnóstico de infeção por HPV conduziu a que o diagnóstico de VIH permanecesse desconhecido até ao estádio de SIDA, altura em que o desenvolvimento de infeção oportunística a Pneumocystis jirovecii motivou investigação etiológica e, deste modo, o estabelecimento do diagnóstico. O desenvolvimento de doença definidora de SIDA, mesmo que cada vez mais raro, associa-se a um estado de imunodeficiência grave, com múltiplas complicações associadas. Deste modo, é fundamental desenvolver protocolos de atuação, tanto ao nível dos cuidados de saúde primários como secundários, que incluam a pesquisa de outras IST perante utentes com resultado positivo para infeção por HPV no rastreio de cancro do colo do útero.

Atualmente as serologias do VIH são um exame rápido e pouco dispendioso, com testes rápidos de quarta geração bastante sensíveis e específicos ${ }^{13}$ embora não estejam disponíveis em muitas das unidades de saúde do país.

Após o estabelecimento do diagnóstico, o médico de família tem o papel de gestor dos cuidados prestados, recorrendo ao apoio dos cuidados de saúde secundários sempre que indicado. No presente caso clínico, a rápida articulação com o serviço de infeciologia do hospital de referência, através da discussão do caso clínico por contacto telefónico e agendamento de consulta hospitalar para o dia seguinte, permitiu assegurar um seguimento célere e adequado em contexto hospitalar.

Atendendo ao impacto do diagnóstico nesta doente, não só a nível pessoal como também a nível familiar e social, foi fundamental manter uma abordagem multidisciplinar, articulando não apenas com o serviço de infeciologia, mas também com o serviço de psiquiatria e psicologia, sendo esta uma das características do médico de família, que tem um papel privilegiado também no seguimento longitudinal de cada utente, numa perspetiva holística e centrada na pessoa e no seu contexto familiar, social e comunitário. 


\section{AGRADECIMENTOS}

Os autores agradecem a colaboração do Dr. Eduardo Sousa, Dra. Joana Amaral e Dr. Luís Eusébio.

\section{REFERÊNCIAS BIBLIOGRÁFICAS}

1. Karabela SN, Yasar KK. Fever of unknown origin: evaluation of 110 classical and HIV-associated cases in the last decade. Hosp Pract. 2020 Jun 10. Online ahead of print.

2. Unger $M$, Karanikas $G$, Kerschbaumer A, Winkler S, Aletaha D. Fever of unknown origin (FUO) revised. Wien Klin Wochenschr. 2016;128(2122):796-801.

3. Cunha $B A$, Lortholary $O$, Cunha $C B$. Fever of unknown origin: a clinical approach. Am J Med. 2015;128(10):1138.e1-e15.

4. Gompf SG, Davis M, Contreras A. Fever of unknown origin (FUO). Medscape [Internet]; 2018 [updated 2021 May 17]. Available from https://emedicine.medscape.com/article/217675-overview

5. Bor DH. Approach to the adult with fever of unknown origin. UpToDate [Internet]; 2019 [updated 2020 Jan 13]. Available from https://www.uptodate.com/contents/approach-to-the-adult-with-fever-of-unknown-origin

6. Hot A, Schmulewitz L, Viard JP, Lortholary O. Fever of unknown origin in HIV/AIDS patients. Infect Dis Clin North Am. 2007;21(4):1013-32.

7. Wright WF, Mackowiak PA. Fever of unknown origin. In: Bennett JE, Dolin R, Blaser MJ, editors. Mandell, Douglas, and Bennett's principles and practice of infectious diseases (Vol. 1). 8th edition. Elsevier Saunders; 2015. p. 721-31.e1. ISBN 9781455748013

8. Gilroy SA, Faragon JJ. HIV infection and AIDS. Medscape [Internet] 2019 [updated 2020 Mar 5]. Available from: https://emedicine.medscape.com/article/211316-overview

9. World Health Organization. HIV/AIDS [homepage].WHO; 2021 Jul 14.Available from: https://www.who.int/news-room/fact-sheets/detail/hiv-aids
10. Direção-Geral da Saúde. Diagnóstico e rastreio laboratorial da infeção pelo vírus da imunodeficiência humana (VIH): norma n. ${ }^{\circ}$ 058/2011, de 28/12/2011, atualizada em 10/12/2014. Lisboa: DGS; 2014.

11. Jemal A, Simard EP, Dorell C, Noone AM, Markowitz LE, Kohler B, et al. Annual report to the Nation on the status of cancer, 1975-2009, featuring the burden and trends in human papillomavirus (HPV)-associated cancers and HPV vaccination coverage levels. J Natl Cancer Inst. 2013;105(3):175-201.

12. Collins S, Rollason TP, Young LS, Woodman CB. Cigarette smoking is an independent risk factor for cervical intraepithelial neoplasia in young women: a longitudinal study. Eur J Cancer. 2010;46(2):405-11.

13. Wang T, Li D, Yan K, Yuan Y, Yang T, Du X, et al. Performance evaluation of a new fourth-generation HIV Ag/Ab combination electrochemiluminescence immunoassay: evaluation of a new HIV assay. Int J STD AIDS. 2014;25(4):267-72.

\section{CONFLITO DE INTERESSES}

Os autores declaram não possuir quaisquer conflitos de interesse.

\section{FONTES DE FINANCIAMENTO}

O trabalho apresentado neste manuscrito não foi objeto de qualquer tipo de financiamento externo (incluindo bolsas e investigação).

\section{ENDEREÇO PARA CORRESPONDÊNCIA}

Cristiana Santos Antunes

E-mail: cristianantunes.1@gmail.com

https://orcid.org/0000-0002-6725-5193

Recebido em 22-12-2020

Aceite para publicação em 19-06-2021 


\section{ABSTRACT}

\section{FEVER OF UNKNOWN ORIGIN: AN UNEXPECTED DIAGNOSIS}

Introduction: Fever of unknown origin (FUO) syndrome is defined as the presence of temperature higher than $38.3^{\circ} \mathrm{C}$ lasting more than three weeks, with failure to reach a diagnosis despite a correct investigation in three outpatient visits or three days in the hospital. It implies a criterion evaluation for general practitioners, leading to a proper diagnostic investigation. Between the large spectrum of possible etiologies, the HIV infection is a possibility to consider, especially if there are associated risk factors.

Case Description: Female, 47 years old, Caucasian, with a history of neoplasm of the cervix submitted to conization four years ago. She is a smoker. Divorced, she belongs to a mono-parental family since 2005 , her last partner was eight years ago. The patient came to an urgent consultation with symptoms of malaise, fatigue, evening fever, and dry cough, for several weeks. After the first steps of investigation, the etiology remained undefined, despite the recurrence of symptoms. Given the clinical condition of FUO syndrome, it was performed a wider etiologic investigation revealed HIV-1 positive serology. The patient was referred to an infectious diseases hospital appointment and started on antiretroviral treatment and therapy directed to pneumocystosis, and acquired immunodeficiency syndrome (AIDS)-defining disease. This diagnosis had a profound influence at a personal, family, and social level with the need for follow-up in psychology and psychiatry consultation.

Commentary: The etiologic investigation of FUO syndrome, in this clinical case, has conducted to an unexpected diagnosis of AIDS, which has sensitized the health team to the importance of a timely HIV screening, for the correct approach of the FOI syndrome and for the importance of longitudinal monitoring by the family physician.

Keywords: HIV infection; Acquired immunodeficiency syndrome; Fever of unknown origin; Pneumocystosis. 